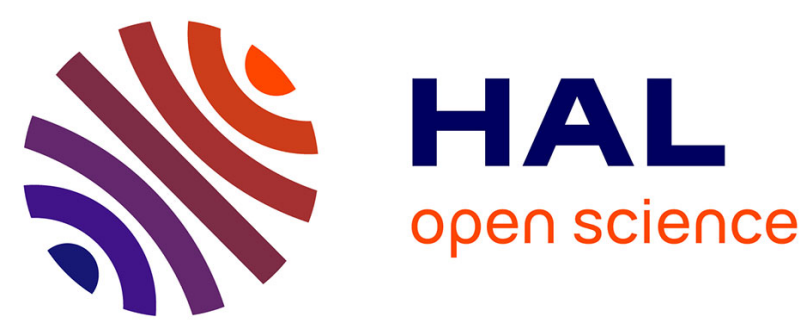

\title{
Thermoelectric properties of co-sputtered CoSb3 thin films as a function of stoichiometry
}

Zhuang-Hao Zheng, Fu Li, Feng Li, Yin-Zhen Li, Ping Fan, Jing-Ting Luo, Guang-Xing Liang, Bo Fan, Ai-Hua Zhong

\section{- To cite this version:}

Zhuang-Hao Zheng, Fu Li, Feng Li, Yin-Zhen Li, Ping Fan, et al.. Thermoelectric properties of cosputtered CoSb3 thin films as a function of stoichiometry. Thin Solid Films, 2017, 632, pp.88-92. 10.1016/j.tsf.2017.04.044 . hal-01542760

HAL Id: hal-01542760

https://hal-univ-rennes1.archives-ouvertes.fr/hal-01542760

Submitted on 5 Jul 2017

HAL is a multi-disciplinary open access archive for the deposit and dissemination of scientific research documents, whether they are published or not. The documents may come from teaching and research institutions in France or abroad, or from public or private research centers.
L'archive ouverte pluridisciplinaire HAL, est destinée au dépôt et à la diffusion de documents scientifiques de niveau recherche, publiés ou non, émanant des établissements d'enseignement et de recherche français ou étrangers, des laboratoires publics ou privés. 


\section{Thermoelectric properties of co-sputtered $\mathrm{CoSb}_{3}$ thin films}

\section{as a function of stoichiometry}

Zhuang-hao Zheng ${ }^{\mathrm{a}, \mathrm{b}}, \mathrm{Fu} \mathrm{Li}{ }^{\mathrm{a}}$, Feng, $\mathrm{Li}^{\mathrm{a}}$, Yin-zhen $\mathrm{Li}^{\mathrm{a}}{ }^{\mathrm{a}}$, , Ping Fan ${ }^{\mathrm{a}, ~}{ }^{*}$, Jing-ting Luo ${ }^{\mathrm{a}}$

*, Guang-xing Liang ${ }^{\mathrm{a}, \mathrm{b}}$, Bo Fan ${ }^{\mathrm{a}}$, Ai-hua Zhong ${ }^{\text {a }}$

a College of Physics and Energy, Institute of Thin Film Physics and Applications, Shenzhen University 518060, China

b Laboratory of Glasses and Ceramics, Institute of Chemical Science UMR CNRS 6226, University of Rennes 1, Rennes 35042, France.

c Shenzhen key laboratory of sensor technology, Shenzhen, 518060, China

Abstract: The skutterudite compound $\mathrm{CoSb}_{3}$ exhibits excellent thermoelectric properties for thermoelectric application. The composition plays an important role in affecting the microstructural and thermoelectric behavior of $\mathrm{CoSb}_{3}$, especially in the form of thin film. In this study, the Co-excess and Sb-excess $\mathrm{CoSb}_{3}$ thin films were prepared by radio frequency and direct magnetron co-sputtering technique. It was found that the thin film with excess Co exhibits a significant n-type conduction behavior and transforms to p-type conduction behavior with $\mathrm{Sb}$ rich. The X-ray diffraction patterns show that either the Co-excess or Sb-excess samples contain skutterudite $\mathrm{CoSb}_{3}$ and a secondary phase $\mathrm{CoSb}_{2}$. Additionally, $\mathrm{Sb}$ can be found in the Sb-excess samples, yet no Co can be observed in the Co-excess samples.

Keyword: skutterudite $\mathrm{CoSb}_{3}$, thermoelectric property, micro-structure

\section{Introduction}

Thermoelectric materials and devices have attracted significant attention for their advantages such as converting waste heat into electricity by the Seebeck effect and using an externally provided current to remove heat from a system under consideration through the Peltier effect [1-2]. Thermoelectric conversion efficiency is characterized by the figure of merit $\mathrm{ZT}=\sigma \mathrm{S}^{2} \mathrm{T \kappa}^{-1}$ and the power factor $\mathrm{PF}=\sigma \mathrm{S}^{2}$, where $\sigma$ is the electrical conductivity $(\mathrm{S} / \mathrm{m}), \mathrm{S}$ is the Seebeck coefficient $(\mu \mathrm{V} / \mathrm{K}), \mathrm{T}$ is the

\footnotetext{
${ }^{*}$ Corresponding author. E-mail:fanping308@126.com
} 
absolute temperature $(\mathrm{K})$ and $\kappa$ is the total thermal conductivity $(\mathrm{W} / \mathrm{m} \mathrm{K})$ [3-4].

Skutterudite compound $\mathrm{CoSb}_{3}$ has drawn much attention in the last decade. It is expected to be a promising thermoelectric material owing to its high carrier concentration, excellent charge carrier mobility, good Seebeck coefficients, and a complex crystal structure [5-6]. Its unit cell consists of 32 atoms, in which Co atoms form eight sub-cubes with pnicogen rings occupying six of them leaving the final two sub-cubes or cages empty [7]. These vacancy sites can be filled by other atoms so that the thermoelectric performance can be modified. The filled atoms are weakly bound to the cage and rattle about their equilibrium position, which results in phonon scattering and reduces the lattice thermal conductivity [8-9]. Further reduction of the lattice thermal conductivity is possible by preparing low-dimensional thin film. The interface and grain boundary in low-dimensional system effectively scatter phonon to reduce the thermal conductivity [10-11]. Hence thermoelectric thin film with quantum confinement effect has considerable potential for acquire high ZT. Savchuk et al. [12] reported a Seebeck coefficient of $-250 \mu \mathrm{V} / \mathrm{K}$ for n-type $\mathrm{CoSb}_{3}$ thin films deposited using direct current sputtering and annealed at $200{ }^{\circ} \mathrm{C}$. Christen et al. [13] had prepared $\mathrm{CoSb}_{3}$ thin films by pulsed laser ablation where the films are p-type with the hall mobility of the order of $50 \mathrm{~cm}^{2} \mathrm{~V}^{-1} \mathrm{~s}^{-1}$. Achieving a high crystallinity degree of $\mathrm{CoSb}_{3}$ thin films is still a challenge. Therefore, the thermoelectric properties of $\mathrm{CoSb}_{3}$ thin films have not yet reached the level of bulk materials [14-15]. The reasons are that the atomic composition of $\mathrm{Co}$ and $\mathrm{Sb}$ is hard to control and the slight excess $\mathrm{Co}$ or $\mathrm{Sb}$ will lead to a big change of the thermoelectric property and micro-stucture behavior of the thin film, especially the unessential presence impurity phases in $\mathrm{CoSb}_{3}$ thin films [2,16-19]. In this study, both Co-rich and Sb-rich skutterudite $\mathrm{CoSb}_{3}$ thin films were deposited on flexible substrate by using radio frequency (RF) and direct magnetic (DC) co-sputtering technique. Then all the thin films were annealed at $325^{\circ} \mathrm{C}$ for $1 \mathrm{~h}$ under a constant flow of argon atmosphere. The influence of excess Co or $\mathrm{Sb}$ on the thermoelectric property and micro-structure of the $\mathrm{CoSb}_{3}$ thin films were investigated.

\section{Experimental details}


Thin film specimens were deposited on flexible substrate under argon atmosphere at room temperature by magnetron co-sputtering technique, which the based pressure was evacuated to an ultrahigh vacuum $\left(6.0 \times 10^{-4} \mathrm{~Pa}\right)$ prior to the deposition. High purity Co (99.99\%), Sb target (99.99\%) and $\mathrm{CoSb}_{3}$ alloy target $(99.5 \%)$ with a diameter of $60 \mathrm{~mm}$ were used. Before deposition, the substrates were ultrasonically cleaned in acetone, alcohol and deionized water for $15 \mathrm{~min}$, respectively. A 5 min pre-sputtering process was performed to remove contaminants on the target surfaces. The working pressure was kept at $0.4 \mathrm{~Pa}$ with Ar of $40 \mathrm{sccm}$. The sputtering power of $\mathrm{CoSb}_{3}$ was fixed at $55 \mathrm{~W}$ by radio frequency magnetron sputtering and the deposition time was $30 \mathrm{~min}$. The $\mathrm{Co}$ or $\mathrm{Sb}$ was co-sputtering with the fixed sputtering power of $10 \mathrm{~W}$ by direct magnetron sputtering when the sputtering process of $\mathrm{CoSb}_{3}$ is half completed and the co-sputtering time was 2, 4, 6 and $8 \mathrm{~min}$, respectively. Then all the thin films was annealed at $325{ }^{\circ} \mathrm{C}$ for $1 \mathrm{~h}$ under Ar atmosphere after the sputtering finished.

The structure of the thin films was studied by X-ray diffraction technique (D/max 2500 Rigaku Corporation) with the angle $2 \theta$ of $20-70{ }^{0}$ with $\mathrm{Cu} \mathrm{K}_{\alpha}$ radiation $(\lambda=0.15406 \mathrm{~nm})$. The composition was characterized by energy dispersive X-ray spectrometer system (EDS, set in the Zeiss supra 55, Zeiss Corporation). The electrical conductivity of the thin films was measured using the four-probe technique with a Keithley 2400 current-voltage measurement (Keithley Corporation). The Seebeck coefficient was measured by Seebeck coefficient measurement system (Panco PSM, Quantum Design Corporation). The carrier concentration of the thin films was tested at room temperature by Van der Pauw Hall measurements (ET9000, Beijing Oriental Technology Corporation). The thin film thickness was obtained by using a DEKTAK3 ST surface-profile measurement system (Veeco).

\section{Results and discussion}

The composition and thickness of all the samples are summarized in Table 1 and Table 2. The Co-excess and Sb-excess samples were marked as S1 S4 and T1 T4, respectively. The undoped thin films which named as S0 or T0 has the $\mathrm{Co}: \mathrm{Sb}$ atomic ratio of $25.5: 74.5$, which has little deflection from the stoichiometry and is Co-rich. 
The composition of Co increases from $25.5 \%$ to $40.6 \%$ after the co-sputtering duration of $\mathrm{Co}$ increased and the $\mathrm{Sb}$ increases $74.5 \%$ to $82.7 \%$ after the co-sputtering duration of $\mathrm{Sb}$ increased.

Fig. 1 shows the XRD patterns of the Co-rich $\mathrm{CoSb}_{3}$ thin films and Fig. 2 shows the XRD patterns of the Sb-rich $\mathrm{CoSb}_{3}$ thin films. As can be seen from Fig. 1, the thin film $\mathrm{S} 0$ prepared by $\mathrm{CoSb}_{3}$ alloy target without any co-sputtering has a main phase of $\mathrm{CoSb}_{3}$ skutterudite. Besides, some impure peaks with very low intensity related to $\mathrm{CoSb}_{2}$ phase can be found, which matched the composition test result. The composition test also indicates that the $\mathrm{Sb}$ content of the thin film is slightly less than the stoichiometric target. The XRD patterns of all the Co-excess samples reveal two main peaks which locate at $\sim 31^{\circ}$ and $\sim 33^{\circ}$. They are indexed as the (310) plane of $\mathrm{CoSb}_{3}$ and the (-121) plane of $\mathrm{CoSb}_{2}$. The intensity of $\mathrm{CoSb}_{2}$ peaks increases with the increasing of Co content and it becomes to the primary phase when the Co content is in the range of $32 \% \sim 39 \%$. However, the intensity of the (310) peak of S4 becomes the highest again when the content reaches $40.6 \%$. In contrast, this peak shifts slightly to larger angle and it tends to be intensified after increasing the Co content. In literature, a peak which relates to the CoSb (101) plane locates between the $\mathrm{CoSb}_{3}$ (310) and the $\mathrm{CoSb}_{2}(-121)$. Additionally, it is much close to the (310) plane. So it can be speculated that the peak might be a mixture peak when the Co content deflects largely from the stoichiometric ratio and leads to the big change of this phenomenon. In addition, it cannot be observed any Co phase in the Co-excess samples, indicating that the additional Co might stay in the compound in the thin film. But more likely, some excess Co might fill into the aforementioned empty cages which leads to better thermoelectric properties [20]. Similarly, the Sb-excess thin films show two main phases (Fig. 2), the skutterudite $\mathrm{CoSb}_{3}$ as the primary phase and $\mathrm{CoSb}_{2}$ as the secondary phase. The intensity of the $\mathrm{CoSb}_{3}$ (310) peak increases with the increasing of $\mathrm{Sb}$ content. When the $\mathrm{Sb}$ content reaches $79.9 \%$ (T3 and T4), the characteristic diffraction peaks of $\mathrm{CoSb}_{2}$ disappear and some peaks related to $\mathrm{Sb}$ phase can be observed, suggesting that the excess Sb carries as the free substance in the thin film. In literature, the litter excess Sb can lead to better thermal stability and thermoelectric 
properties [21].

The carrier concentration and carrier mobility of the thin films with different Co and $\mathrm{Sb}$ deposition time are shown in Figure 3. From Fig. 3 (a), we can find that the carrier concentration and carrier mobility of the thin film specimens increase firstly and then decrease when the Co deposition duration increases to $8 \mathrm{~min}$. However, the carrier mobility of the thin film shows much stability at the range of $\sim 0.10 \mathrm{~cm}^{2} \mathrm{~V}^{-1} \mathrm{~s}^{-1}$. In contrast, a strong increase of the carrier concentration can be observed. The sample $\mathrm{S} 3$ reaches to $1.5 \times 10^{23} \mathrm{~cm}^{-3}$ when the Co content is above $39.7 \%$ and it shows a typical behavior of heavily doped semiconductor. As it can be seen, higher Co-excess can have higher carrier concentration and leads to the better electrical property. Different result is obtained from Fig. 3 (b), that the carrier concentration of Sb-rich series $\mathrm{T} 1 \sim \mathrm{T} 4$ decreases rapidly from $\sim 1.3 \times 10^{22} \mathrm{~cm}^{-3}$ to $0.1 \times 10^{22} \mathrm{~cm}^{-3}$ when the $\mathrm{Sb}$ content increases. In contrast, the mobility increases sharply and the sample T4 achieves to a big value of $\sim 11 \mathrm{~cm}^{2} \mathrm{~V}^{-1} \mathrm{~s}^{-1}$ which is almost 100 times bigger than the stoichiometric $\mathrm{CoSb}_{3}$. Generally, higher carrier mobility will lead to a better thermoelectric property [22].

The Seebeck coefficient and electrical conductivity of the Co-excess and Sb-excess thin films are shown in Fig. 4 and Fig.5. It can be seen from Fig. 4 that all the Co-excess thin films have a negative Seebeck coefficient indicating they are n-type semiconductor. By prolonging the Co deposition time, the Seebeck coefficient of the $\mathrm{CoSb}_{3}$ thin films decreases and achieves to a very low value of $-11 \mu \mathrm{VK}^{-1}$ when the Co content is above $\sim 39.7 \%$. However, the electrical conductivity of the Co-rich samples increases, and can reach a very high value. This can be explained by the strong increase of the carrier concentration. Similarly, the electrical conductivity of the $\mathrm{Sb}$-excess thin films is enhanced to a very high value of $1.0 \times 10^{5} \mathrm{Sm}^{-1}$ when the $\mathrm{Sb}$ content reaches $\sim 82.7 \%$. This is due to its very large carrier mobility. But unlike the result of the Co-excess samples, the Seebeck coefficient of the Sb-excess samples transforms from negative to positive, indicating the thin films change from n-type conduction behavior to p-type conduction behavior. It can be explained by self-doping of the Sb-rich samples by the excess $\mathrm{Sb}$. When the $\mathrm{Sb}$ content is $82.7 \%$, the absolute 
value is about $26 \mu \mathrm{VK}^{-1}$ which is the largest value within the entire sample group. The PF $\left(\sigma S^{2}\right)$ has been calculated and the highest value of the Co-rich samples is $2.4 \times 10^{-4}$ $\mathrm{Wm}^{-1} \mathrm{~K}^{-2}$ and the Sb-rich samples is $6.9 \times 10^{-4} \mathrm{Wm}^{-1} \mathrm{~K}^{-2}$, while the pristine sample is $0.6 \times 10^{-4} \mathrm{Wm}^{-1} \mathrm{~K}^{-2}$. It can be acquired that both of the Co and $\mathrm{Sb}$ excess can improve the thermoelectric property of the $\mathrm{CoSb}_{3}$ thin film. Moreover, the $\mathrm{Sb}$ excess is more effective to improve the thermoelectric property of the $\mathrm{CoSb}_{3}$ thin film.

\section{Conclusions}

The Co-excess and Sb-excess $\mathrm{CoSb}_{3}$ based thin films were prepared to study the thermoelectric property and micro-structure behavior. Appropriate $\mathrm{Co}$ or $\mathrm{Sb}$ can improve the electrical conductivity of the thin films. Especially, the Sb-excess thin films have large carrier mobility which leads to better electrical property and higher Seebeck coefficient. The power factor of the Sb-excess sample has a high value of 6.9 $\times 10^{-4} \mathrm{Wm}^{-1} \mathrm{~K}^{-2}$ which is ten times of the $\mathrm{CoSb}_{3}$ thin film. So it can be speculated that the $\mathrm{Sb}$ might be the key decisive on the thermoelectric property and micro-structure behavior of the thin film.

\section{Acknowledgements}

Z.H. Zheng, F. Li and G.X. Liang contributed equally. Supported by National Natural Science Foundation of China (No. 11604212), Key platform and research projects, Education and Research of Guangdong Province (2015KQNCX139), Basical Research Program of Shenzhen (JCYJ20160307113206388 and JCYJ20160422102622085).

\section{References}

[1] L.E. Bell, Cooling, heating, generating power, and recovering waste heat with thermoelectric systems, Science, 321 (2008) 1457-1461.

[2] X. Shi, J. Yang, J.R. Salvador, M.F. Chi, J.Y. Cho, H. Wang, S.Q. Bai, J.H. Yang, W.Q. Zhang, L.D. Chen, Multiple-filled skutterudites: high thermoelectric figure of merit through separately optimizing electrical and thermal transports, J. Am. Chem. Soc. 133 (2011) 7837-7846.

[3] G.S. Fu, L. Zuo, J. Chen, M. Lu, L.Y. Yu, Thermoelectric properties of DC-sputtered filled skutterudite thin film, J. Appl. Phys. 117 (2015) 
$1253041-1253017$.

[4] P. Fan, Z.H. Zheng, Z.K. Cai, T.B. Chen, P.J. Liu, X.M. Cai, D.P. Zhang, G.X. Liang, J.T. Luo, The high performance of a thin film thermoelectric generator with heat flow running parallel to film surface, Appl. Phys. Lett. 102 (2013) 0339041-0339043.

[5] D.T. Morelli, G.P. Meisner, B. Chen, S. Hu, C. Uher, Cerium filling and doping of cobalt triantimonide, Phys. Rev. B 56 (1997) 7376-7383.

[6] T. Caillat, A. Borshchevsky, J.P. Fleurial, Properties of single crystalline semiconducting $\mathrm{CoSb}_{3}$, J. Appl. Phys. 80 (1996) 4442-4449.

[7] G.J. Snyder, E.S. Toberer E S, Complex thermoelectric materials, Nat. Mater. 7 (2008) 105-114.

[8] T. He, J.Z. Chen, H. David Rosenfeld, M. A. Subramanian, Thermoelectric properties of indiumfilled skutterudites, Chem. Mater. 18 (2006) 759-762.

[9] G.S. Nolas, H. Takizawa, T. Endo, H. Sellinschegg, D.C. Johnson, Thermoelectric properties of Sn-filled skutterudites, Appl. Phys. Lett. 77 (2000) 52-54.

[10] L.D. Hicks, M.S. Dresslhaus, Thermoelectric figure of merit of a one-dimensional conductor, Phys. Rev. 47 (1993) 16631-16634.

[11] R. Venkatasubramanian, E. Siivola, T. Colpitts, B. O' Quinn, Thin-film thermoelectric devices with high room-temperature figures of merit, Nature 413 (2001) 597-602.

[12] V. Savchuk, A. Boulouz, S. Chakraborty, J. Schumann, H. Vinzelberg, Transport and structural properties of binary skutterudite $\mathrm{CoSb}_{3}$ thin films grown by $\mathrm{dc}$ magnetron sputtering technique, J. Appl. Phys. 92 (2002) 5319-5326.

[13] H. M. Christen, D. G. Mandrus, D. P. Norton, L. A. Boatner, B. C. Sales, Properties of $\mathrm{CoSb}_{3}$ films grown by pulsed laser ablation, Mater. Res. Soc. Symp. Proc. 478 (1993) 217-220.

[14] P. Fan, Y. Zhang, Z.H. Zheng, W.F. Fan, J.T. Luo, G.X. Liang, D.P. Zhang, Thermoelectric properties of cobalt antimony thin films deposited on flexible substrates by radio frequency magnetron sputtering, J. Electron. Mater., 44 (2015) $630-635$ 
[15] P.F. Wen, P. Li, Q.J. Zhang, Z.W. Ruan, L.S. Liu, P.C. Zhai, Effects of annealing on microstructure and thermoelectric properties of nanostructured $\mathrm{CoSb}_{3}, \mathrm{~J}$. Electron. Mater. 42 (2013) 1443-1448.

[16] W.S. Liu, B.P. Zhang, J.F. Li, L.D. Zhao, Thermoelectric property of fine-grained $\mathrm{CoSb}_{3}$ skutterudite compound fabricated by mechanical alloying and spark plasma sintering, J. Phys. D: Appl. Phys. 40 (2007) 566-572.

[17] Y. Kajikawa, Analysis of high-temperature thermoelectric properties of p-type $\mathrm{CoSb}_{3}$ within a two-valence-band and two-conduction-band model, J. Appl. Phys. 115 (2014) 2037161-2037169.

[18] A.L.E. Smalley, S. Kim, D.C. Effects of Composition and Annealing on the Electrical Properties of $\mathrm{CoSb}_{3}$, Johnson, Chem. Mater. 15 (2003) 3847-3851.

[19] C. Park, Y. Kim, Atomic and Electronic Structures of Co-related point defects in $\mathrm{CoSb}_{3}$, J. Electron. Mater. 40 (2011) 962-966.

[20] G.A. Lamberton, S. Bhattacharya, R.T. Litteton, M.A. Kaeser, R.H. Tedstrom, T.M. Tritt, J. Yang, G.S. Nolas, High figure of merit in Eu-filled $\mathrm{CoSb}_{3}$-based skutterudites, Appl. Phys. Lett. 80 (2002) 598-600.

[21] P. J. Kelly, R. D. Arnell, Magnetron sputtering: a review of recent developments and applications, Vacuum 56 (2000) 159-172.

[22] M.V. Daniel, M. Friedemann, J. Franke, M. Albrecht, Thermal stability of thermoelectric $\mathrm{CoSb}_{3}$ skutterudite thin films, Thin Solid Film, 589 (2015) 203-208. 


\section{Figure Captions}

Fig. 1 X-ray diffraction patterns of the $\mathrm{CoSb}_{3}$ based thin films as a function of Co co-sputtering time.

Fig. 2 X-ray diffraction patterns of the $\mathrm{Sb}$ excess thin films as a function of $\mathrm{Sb}$ co-sputtering time.

Fig. 3 The carrier concentration and Hall mobility of the thin films as a function of deposition time. (a) Co-excess, (b) Sb-excess.

Fig. 4 The Seebeck coefficient and Electrical conductivity of the Co rich thin films as a function of Co co-sputtering time.

Fig. 4 The Seebeck coefficient and Electrical conductivity of the Sb excess thin films as a function of $\mathrm{Sb}$ co-sputtering time. 
Table 1 The composition and thickness of the samples as a function of $\mathrm{Co}$ and $\mathrm{CoSb}_{3}$ co-sputtering time by EDS and surface-profile measurement system analyzed.

\begin{tabular}{ccccc}
\hline Sample & Time (min) & Co (at.\%) & Sb (at.\%) & Thickness (nm) \\
\hline S0/T0 & 0 & 25.5 & 74.5 & 246 \\
S1 & 2 & 31.6 & 68.4 & 270 \\
S2 & 4 & 37.2 & 62.8 & 321 \\
S3 & 6 & 39.7 & 60.3 & 360 \\
S4 & 8 & 40.6 & 59.4 & 416 \\
\hline
\end{tabular}

Table 2 The composition and thickness of the samples as a function of $\mathrm{Sb}$ and $\mathrm{CoSb}_{3}$ co-sputtering time by EDS and surface-profile measurement system analyzed.

\begin{tabular}{ccccc}
\hline Sample & Time (min) & Co (at.\%) & Sb (at.\%) & Thickness (nm) \\
\hline T1 & 2 & 23.7 & 76.3 & 253 \\
T2 & 4 & 21.3 & 78.7 & 265 \\
T3 & 6 & 20.1 & 79.9 & 288 \\
T4 & 8 & 17.3 & 82.7 & 331 \\
\hline
\end{tabular}




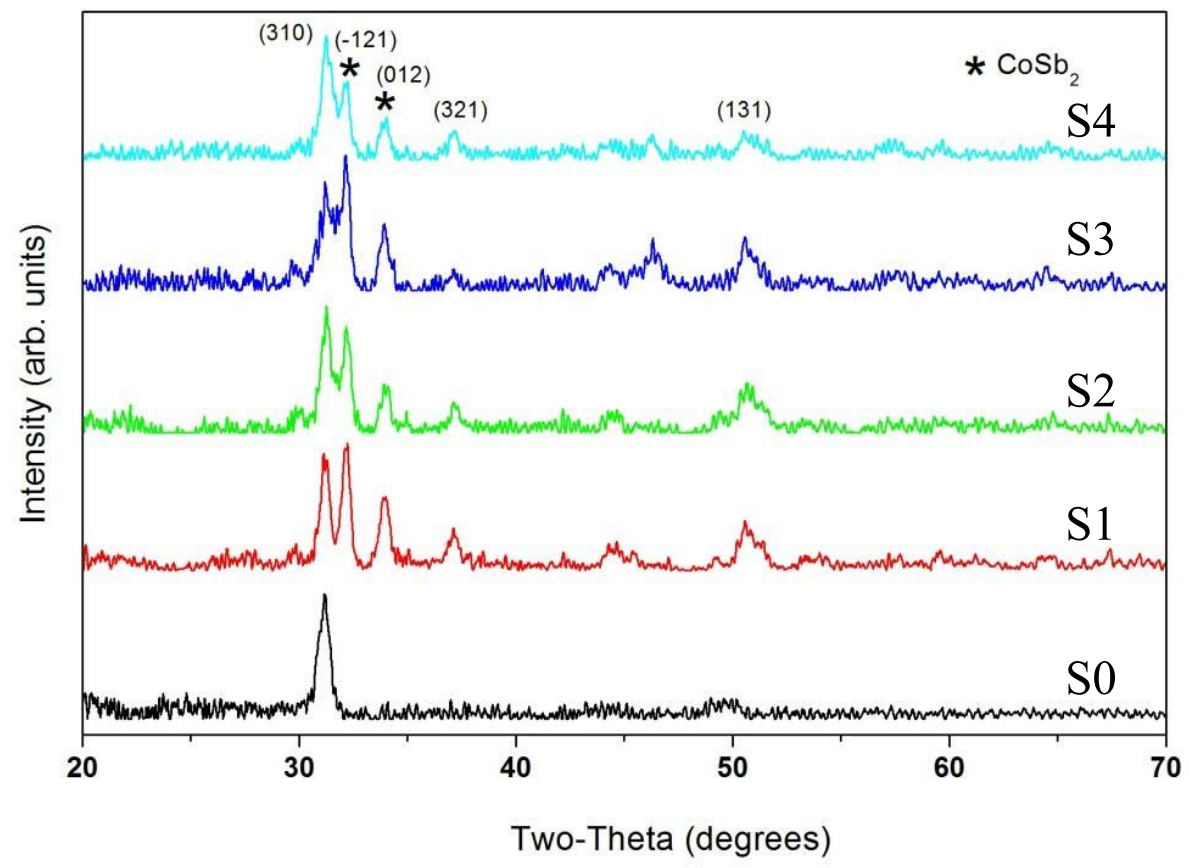

Fig. 1

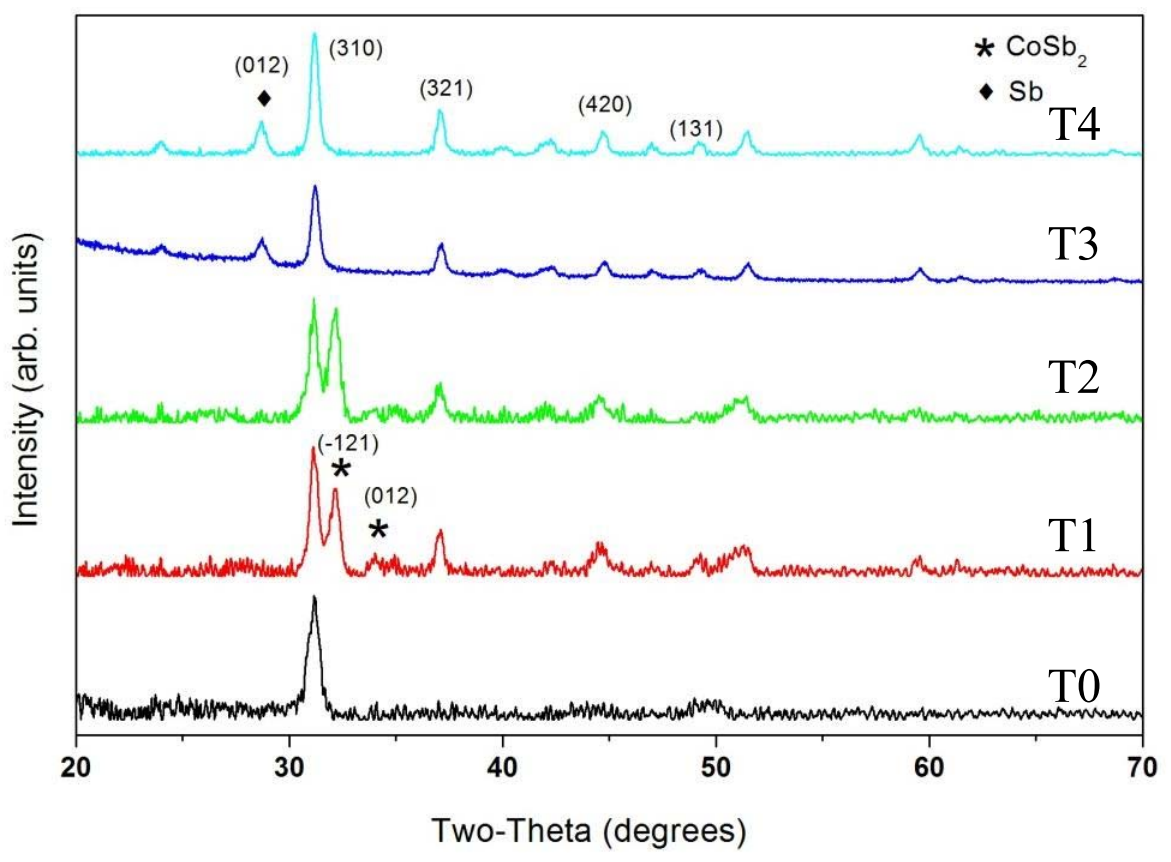

Fig. 2 

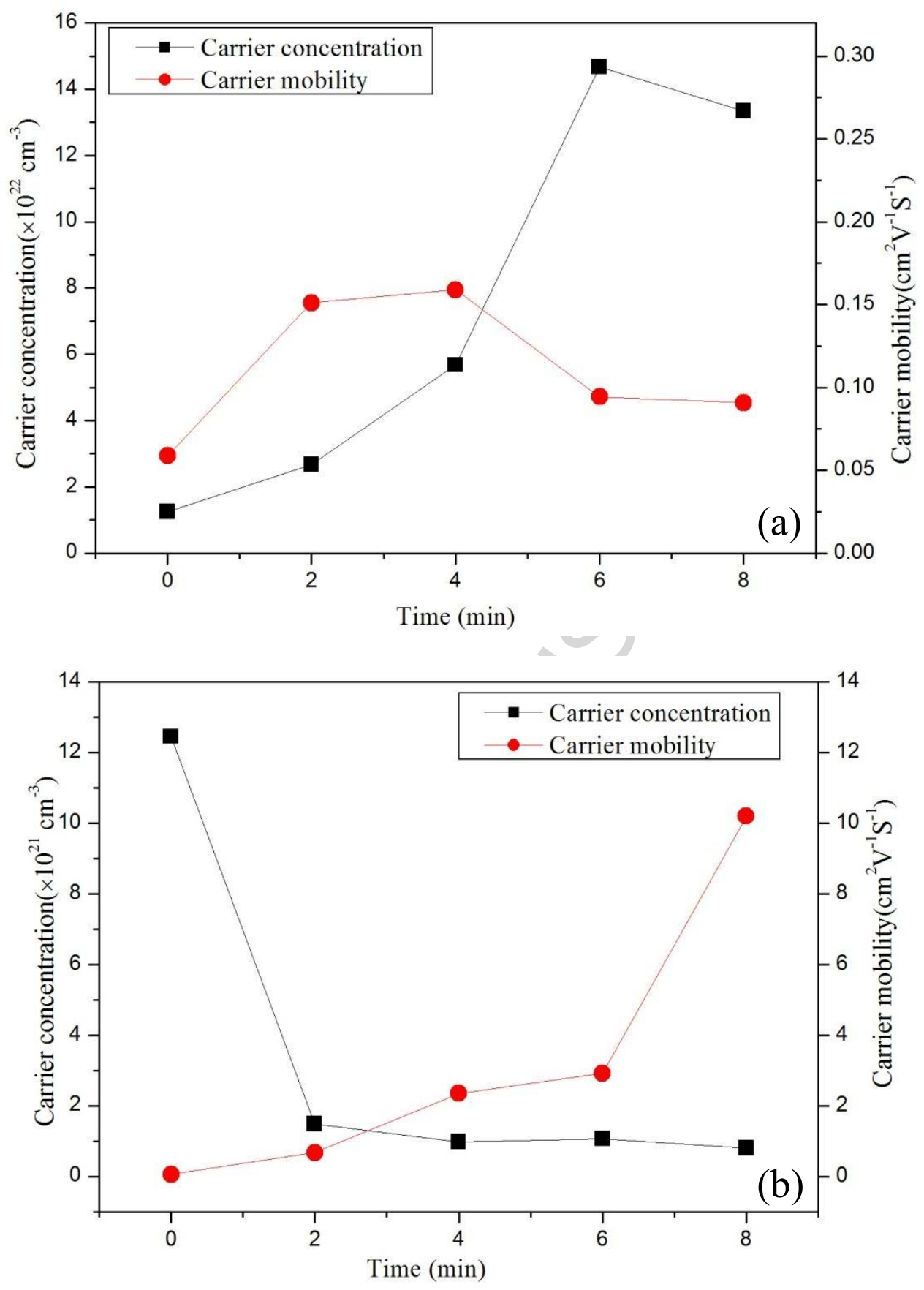

Fig. 3 


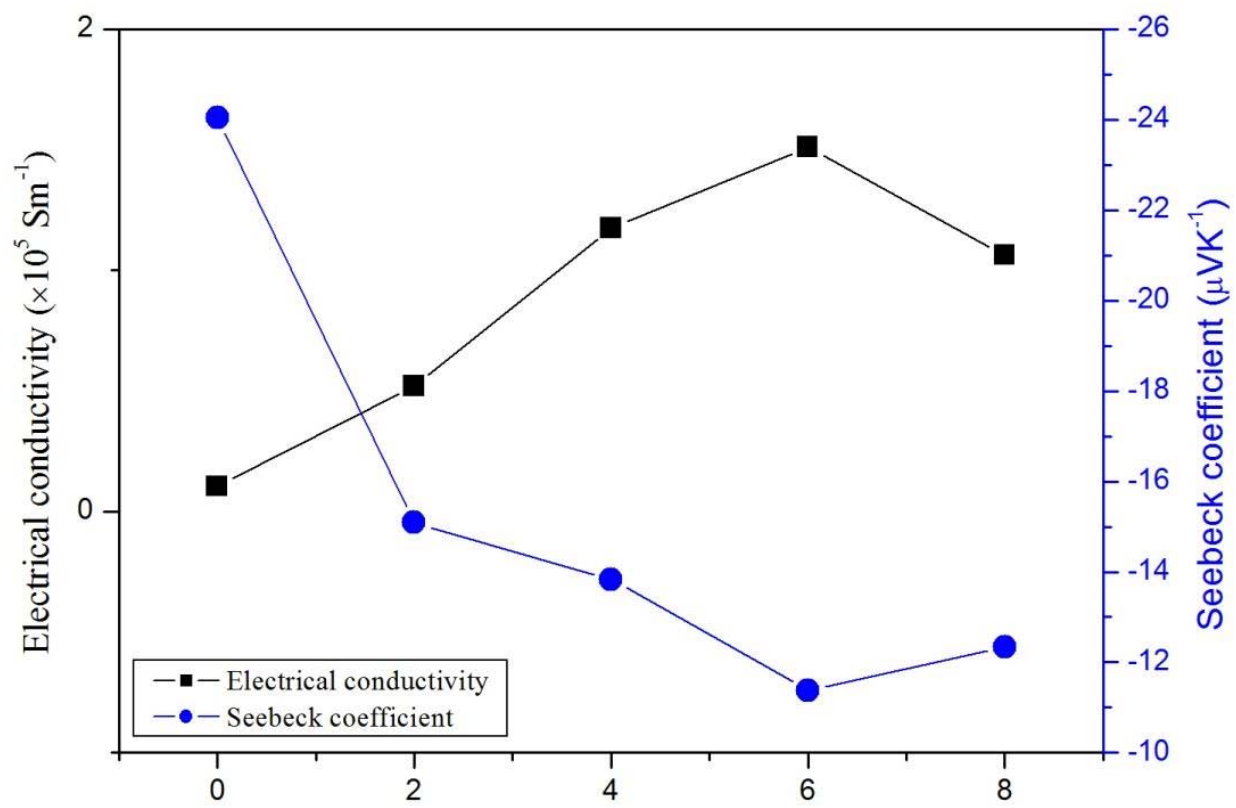

Time (min)

Fig. 4

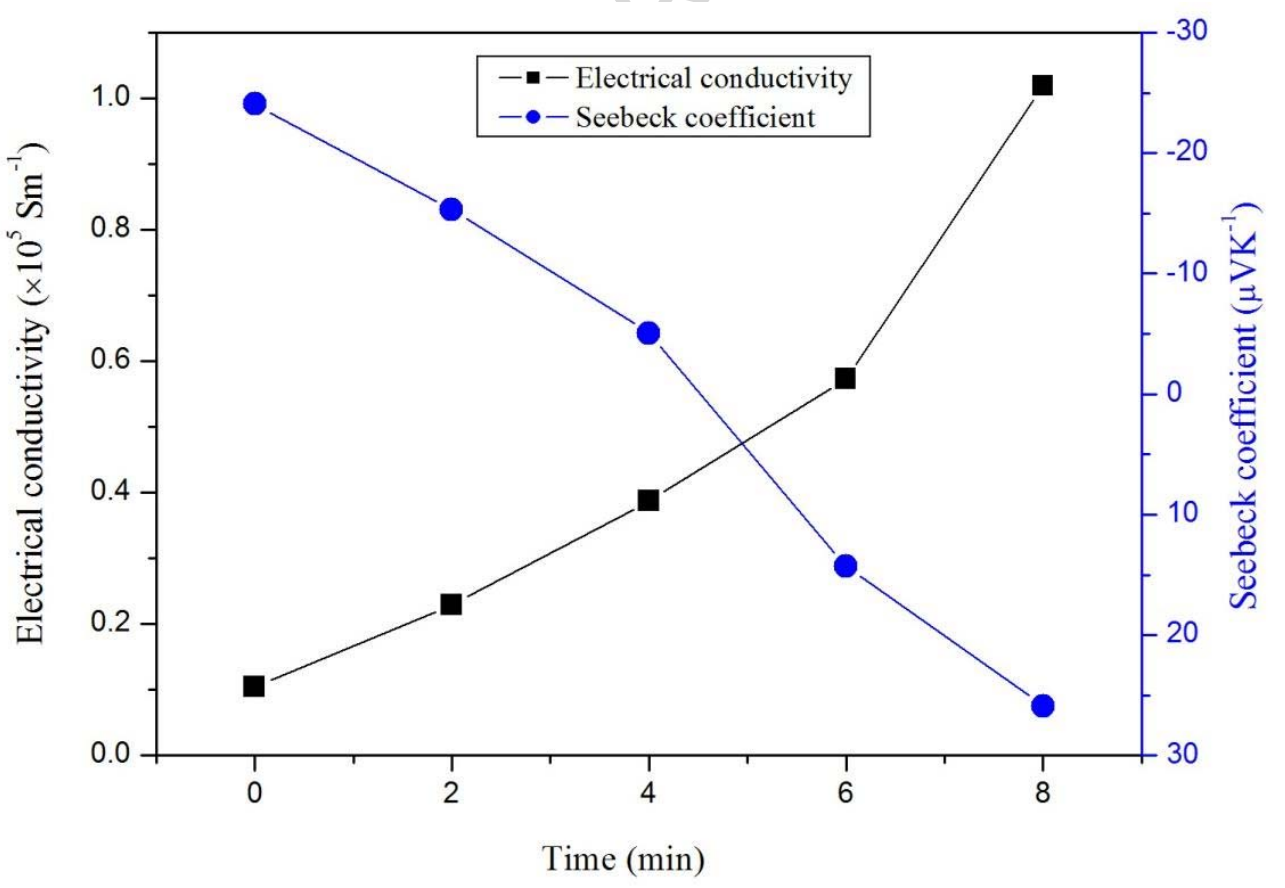

Fig. 5 


\section{Highlights}

- The Co-excess and Sb-excess $\mathrm{CoSb}_{3}$ thin films were prepared by co-sputtering method.

- Co or Sb riches can both improve the electrical conductivity of the thin films.

- The power factor of the Sb-excess sample is ten times of the $\mathrm{CoSb}_{3}$ thin film. 